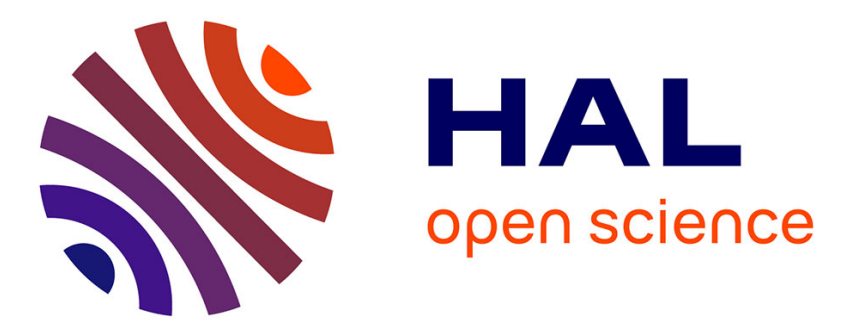

\title{
Wideband and Compact 3-D Quadrature Coupler for 5G Applications
}

\author{
Audrey Cayron, Christophe Viallon, Ayad Ghannam, Alessandro Magnani, \\ Thierry Parra
}

\section{- To cite this version:}

Audrey Cayron, Christophe Viallon, Ayad Ghannam, Alessandro Magnani, Thierry Parra. Wideband and Compact 3-D Quadrature Coupler for 5G Applications. 2019 49th European Microwave Conference (EuMC), Oct 2019, Paris, France. pp.129-132, 10.23919/EuMC.2019.8910742 . hal-02447401

\author{
HAL Id: hal-02447401 \\ https://hal.science/hal-02447401
}

Submitted on 21 Jan 2020

HAL is a multi-disciplinary open access archive for the deposit and dissemination of scientific research documents, whether they are published or not. The documents may come from teaching and research institutions in France or abroad, or from public or private research centers.
L'archive ouverte pluridisciplinaire HAL, est destinée au dépôt et à la diffusion de documents scientifiques de niveau recherche, publiés ou non, émanant des établissements d'enseignement et de recherche français ou étrangers, des laboratoires publics ou privés. 


\title{
Wideband and Compact 3-D Quadrature Coupler for 5G Applications
}

\author{
Audrey Cayron $^{\# 1}$, Christophe Viallon ${ }^{\# 2}$, Ayad Ghannam ${ }^{* 3}$, Alessandro Magnani ${ }^{* 4}$, Thierry Parra ${ }^{\# * 5}$ \\ "LAAS-CNRS, Université de Toulouse, CNRS, INSA, UPS, France \\ *3DiS Technologies, France \\ \{1 acayron, ${ }^{1}$ cviallon, ${ }^{5}$ parra $\} @$ laas.fr, $\left\{{ }^{3}\right.$ ayad.ghannam, ${ }^{4}$ alessandro.magnani $\} @ 3$ dis-tech.com
}

\begin{abstract}
A wideband and compact quadrature coupler intended for 5G applications is presented. The circuit is integrated using a dedicated cost-effective three-dimensional (3-D) technology and is implemented from a 3-D transformer along with Metal-Insulator-Metal (MIM) capacitors that ensure a very good compactness. The coupler's area does not exceed $0.11 \mathrm{~mm}^{2}$. The measurements show good performance over a bandwidth of $7 \mathrm{GHz}$ ranging from $19.5 \mathrm{GHz}$ to $26.5 \mathrm{GHz}$. Within this whole band, insertion losses remain better than $0.6 \mathrm{~dB}$ whereas a phase difference between both outputs of $90^{\circ}$ is achieved with a maximum deviation of $3^{\circ}$.
\end{abstract}

Keywords - 3-D technology, 5G mobile application, integrated passive device (IPD), K-band, quadrature couplers, transformer.

\section{INTRODUCTION}

Signal power splitting or combining is largely required in microwave circuits, and a lot of passive topologies fulfilling these functions have been introduced. Among all devices, directional coupler hold a central place, especially the $3 \mathrm{~dB}$ quadrature coupler, since it is a main component for balanced circuits and I/Q transceivers, in radar detection, or in antenna monitoring networks, such as for beamforming. Such a coupler is mainly based on branch-line, rat-race or coupled line topologies. Thus, when it is fabricated using planar technologies, many issues are resulting since the length of lines is a significant fraction of signal wavelength (typically $\lambda / 4)$. Indeed, the influence of substrate parameters on the characteristics of these sections of lines have a significant effect on performance, especially when the frequency is increasing, and on integration density. This question is particularly relevant for future consumer $5 \mathrm{G}$ terminals that will operate in the $\mathrm{K}$ and $\mathrm{Ka}$ frequency bands, with a difficult trade-off between cost, performance and compactness.

Several strategies exist to reduce the length of transmission lines. For instance, pattern shields [1], slow-wave techniques [2], or stubs added at transmission line ends [3] can be used. Replacing the lines by meanders also helps in reducing dimensions. One last approach consists in fully replacing transmission lines by lumped-elements. Using this technique, circuit compactness is drastically improved $\left(0.016 \mathrm{~mm}^{2}\right.$ in [4]), especially when they are integrated using CMOS or BiCMOS technologies, where small metal widths are available. Nevertheless, when lumped-elements are used, usually bandwidth is reduced and insertion losses are increased.
From the above, the low-cost integration of a coupler reaching high levels of performance over a large bandwidth with a reduced footprint remains a challenge. So, we propose the vertical dimension investigation by presenting a coupler based on lumped-elements designed to be integrated using a cost-effective 3-D IPD technology. The objective is to cover $5 \mathrm{G}$ standard in frequency bands ranging from $20 \mathrm{GHz}$ to $28 \mathrm{GHz}$.

The paper is organized as follows. The 3-D IPD technology used to fabricate the presented coupler is summarized in section II. The optimization of the circuit is then developed in section III, with emphasis on the design of the 3-D transformer forming the inductive part of the coupler. Finally, the characterization of the circuit is discussed in section IV.

\section{3-D IPD FABRICATION PROCESS}

The 3-D IPD technology presented here is an evolution of the version published in [5] that includes the fabrication of MIM capacitors along with 3-D solenoids and transformers. The cross-sectional view of this process is shown in Fig. 1. It has been applied on a glass substrate for the fabrication of the circuits presented in this paper. Only six mask levels are required for the whole process built from the different steps summarized below.

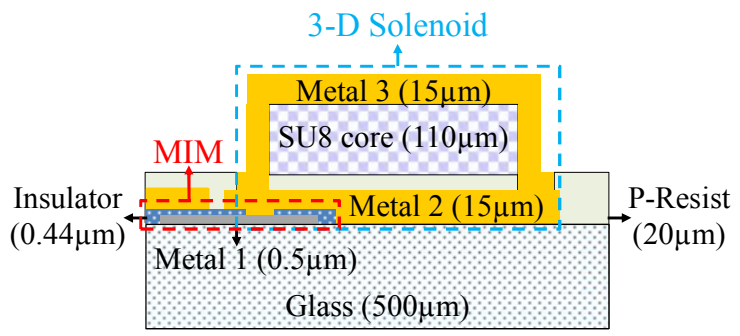

Fig. 1. Cross-sectional view of the 3-D IPD process.

First, the bottom electrode of the MIM capacitor (Metal 1) is formed by a $0.5 \mu \mathrm{m}$-thick sputtered aluminium layer and a lift-off process. A thin layer of $\mathrm{Si}_{\mathrm{x}} \mathrm{N}_{\mathrm{y}}$ is deposited using a low-temperature ICPCVD process $\left(<100^{\circ} \mathrm{C}\right)$ to make up the insulating layer (Insulator). The top electrode is manufactured along with the first level of the solenoid in one copper-electroplating step (Metal 2). This solution helps in reducing the number of process steps and the overall cost. 
Then, a passivation resist (P-Resist) is deposited to protect the first copper level from oxidation and degradation during following steps. A $110 \mu \mathrm{m}$-thick SU8 photoresist layer is deposited and patterned to form the solenoid core. Vias are opened in the P-resist layer to connect the bottom to the top metal level of the solenoid. Finally, the vertical and upper metal sections of the solenoid are fabricated in a resist mold by involving a single copper electroplating step (Metal 3). The highest process temperature does not exceed $150^{\circ} \mathrm{C}$, making the integration on PCB substrate like FR4 (Tg temperature around $180^{\circ} \mathrm{C}$ ) possible, as well as above-IC integration.

\section{COUPLER DESIGN GUIDELINES}

The common coupled line coupler can be modelled by the four-port network of Fig. 2, where transmission lines are replaced by their equivalent LC $\pi$-network. Replacing the pair of coupled inductors by a 1:1 transformer leads to a new coupler whose coupling factor now depends on the one of the transformer $(\mathrm{K}=\mathrm{M} / \mathrm{L})$ and on the inter-wire capacitance, modelled by $C_{c}$ in Fig. 2. These parameters are related with the transformer's geometry i.e. wire thickness and width, inter-wire spacing and wire length. The overall length of primary and secondary coils sets the central operating frequency of the final coupler.

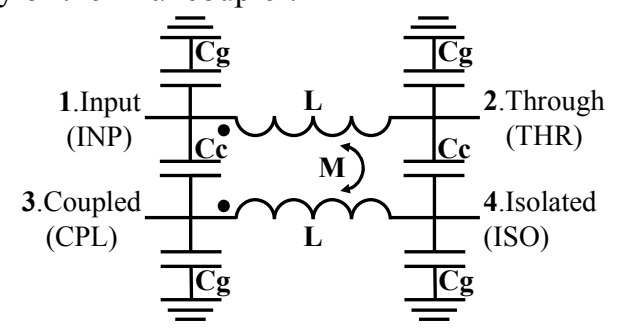

Fig. 2. Lumped-element network of a coupled line quadrature coupler.

The first idea is to build the transformer from two solenoids intertwined in a perfectly symmetrical way, as suggested in Fig. 3.

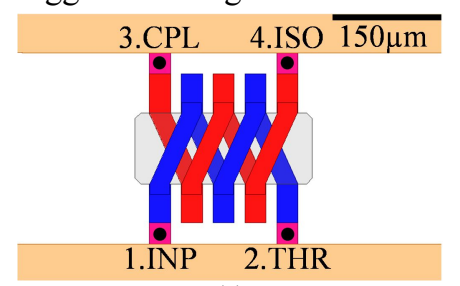

(a)

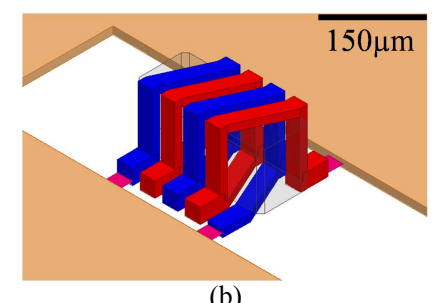

(b)
Fig. 3. Design capture of the first designed 3-D transformer: (a) top view; (b) 3-D view.

With this topology, the input (1) and through (2) ports of the first solenoid (in blue) are located on the same side, whereas coupled (3) and isolated (4) ports of the second solenoid (in red) are placed on the opposite side of the transformer. This configuration enables a strong positive mutual inductance that significantly reduces the strip length required to reach a given coupling factor when compared to the usual planar coupled line couplers.

The device is built around a SU8 core featuring a $110 \mu \mathrm{m} \times 110 \mu \mathrm{m}$ square-shaped section. The number of turns of each coil is set to 2, and conductors' width and spacing have been tuned to $30 \mu \mathrm{m}$ and $15 \mu \mathrm{m}$, respectively by using an electromagnetic simulation software (ANSYS HFSS). These values correspond to the best trade-off between $Q$-factor levels in K-band and technology capabilities.

The simulation results of the transformer of Fig. 3 are plotted in Fig. 4. It can be noted that both forward and coupled transmissions, $\left|S_{21}\right|$ and $\left|S_{31}\right|$, respectively, have the same value only at the frequency of $20 \mathrm{GHz}$ (the bandwidth is very narrow) and that their value is $-4 \mathrm{~dB}$, a value quite far from the theoretical $-3 \mathrm{~dB}$. Moreover, a significant phase deviation is observed beyond this frequency. The poor isolation $\left|S_{41}\right|$ and the high return losses $\left|S_{11}\right|$ seen at $20 \mathrm{GHz}$ also indicate that the coupler resulting from the integration of this transformer will not be well balanced.

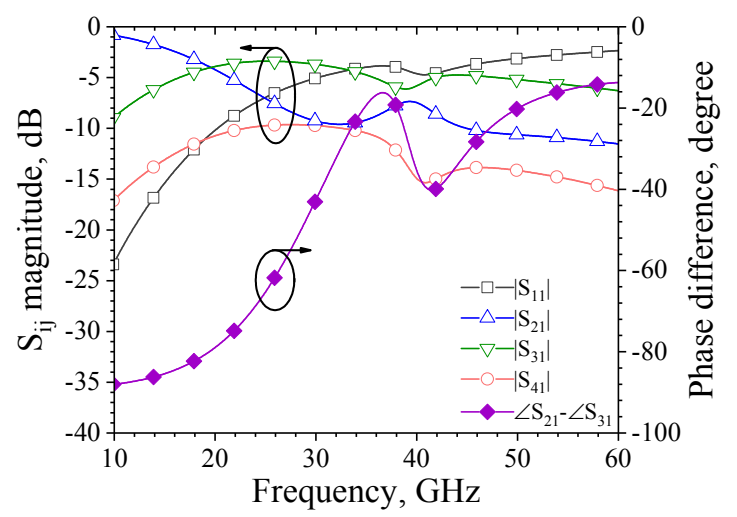

Fig. 4. Simulated S-parameter magnitudes and phase difference between port 2 and port 3 for a signal applied at port 1 for the transformer of Fig. 3.

In order to find origins of such issues, the transformer of Fig. 3 is modelled with a simplified equivalent circuit highlighting how coupling takes place between the two pair of wires, as illustrated in Fig. 5a. In this figure, the coupled wires constituting the transformer are divided into two sections: the vertical plus the upper part, and the bottom side. Such representation highlights that the geometric symmetry of the structure does not translate into an electrical symmetry. The coupled (3) and input (1) ports are shifted by a length of $0.38 \times l$, with $l$ the length of one coil. On the other side, isolation port (4) is shifted by $0.11 \times l$ from the through port (2). These offsets add a phase imbalance between primary and secondary coils that is getting worse as the frequency is increasing, as illustrated by the phase difference curve of Fig. 4. The consequence is a decrease of the coupling efficiency and a poor directivity that cannot be corrected easily.

With the aim of removing previous offsets and recovering the electrical symmetry, the design of the transformer is slightly modified to match the equivalent model of Fig. $5 \mathrm{~b}$. The new layout is shown in Fig. 6. The main difference with previous version is that the four ports are now aligned at the same side of the device. All the dimensions of the previous transformer have been kept, i.e. the core section and form-factor, the width, thickness, and length of the wires as well as wire spacing. The simulation data reported in Fig. 7 show that this new implementation significantly improves the 
behavior of the transformer. The return losses $\left|\mathrm{S}_{11}\right|$ decrease to $-12 \mathrm{~dB}$ at worst, the directivity improves since the magnitude of the isolated port $\left|S_{41}\right|$ reduces from $-10 \mathrm{~dB}$ to $-25 \mathrm{~dB}$ at worst, and a nearly $3 \mathrm{~dB}$ coupling is now observed over a wide bandwidth starting from $30 \mathrm{GHz}$ to $50 \mathrm{GHz}$. The flatness of the phase shift between through and coupled ports is really improved and remains around $90^{\circ}$ on the whole band. Finally, forward transmission $\left|S_{21}\right|$ and coupled transmission $\left|S_{31}\right|$ exhibit a slight over-coupling due to the close proximity of solenoids. This imperfection can be removed by increasing the line spacing up to $17 \mu \mathrm{m}$.

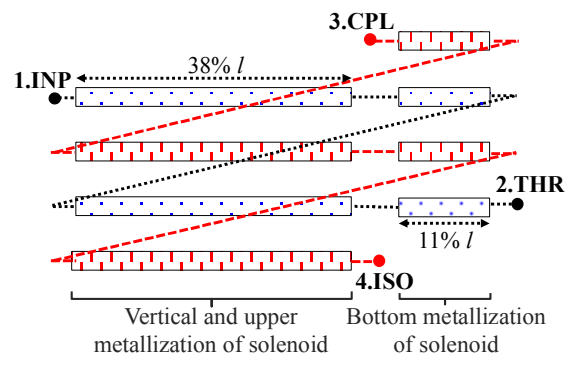

(a)

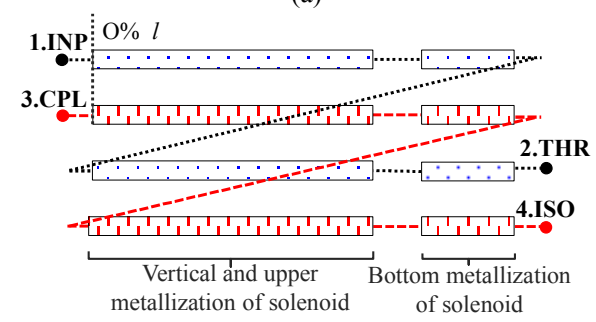

(b)

Fig. 5. Equivalent circuit of the 3-D transformer for the configuration of (a) Fig. 3 and (b) Fig. 6.

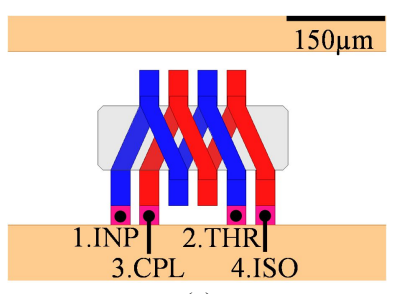

(a)

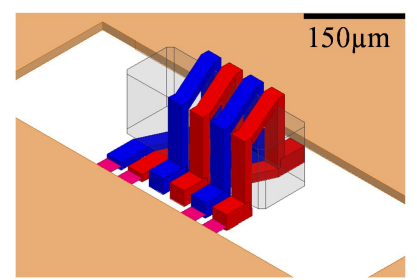

(b)
Fig. 6. Design capture of the second configuration of the 3-D transformer: (a) top view; (b) 3-D view.

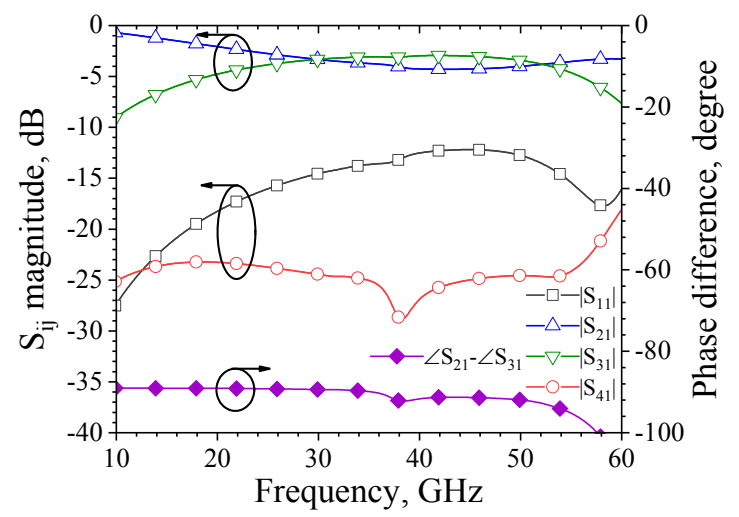

Fig. 7. Simulated S-parameter magnitudes and phase difference between port 2 and port 3 for a signal applied at port 1 for the transformer of Fig. 6.
Based on this last transformer, the final coupler implementation is given in Fig. 8. Instead of setting the spacing to $17 \mu \mathrm{m}$ as mentioned above, adding coupling capacitors $C_{c}$ of $70 \mathrm{fF}$ (as proposed in Fig. 2) has been preferred. The spacing is kept at $15 \mu \mathrm{m}$ to improve the $3 \mathrm{~dB}$ coupling and to maintain compact dimensions. These capacitors have been integrated under transformer ports and do not occupy any additional area. Moreover, Fig. 8 shows that extra capacitors $C_{m 1}$ and $C_{m 2}$ are added in series with coupler ports, with values of $215 \mathrm{fF}$ and $254 \mathrm{fF}$, respectively, to improve return losses $\left|S_{11}\right|$ and isolation $\left|S_{41}\right|$.

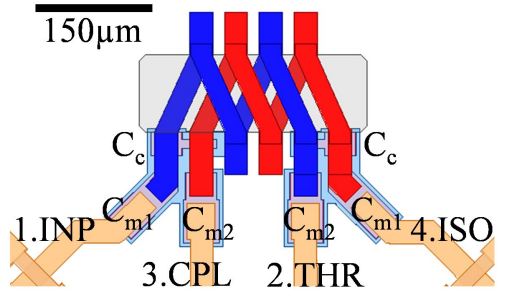

Fig. 8. Design capture (top view) of 3-D quadrature coupler.

\section{PERFORMANCE RESUlts}

The fabricated $3 \mathrm{~dB}$ quadrature coupler is shown in Fig. 9. The circuit occupies an area of $0.11 \mathrm{~mm}^{2}(0.30 \mathrm{~mm} \times 0.37 \mathrm{~mm})$. Its footprint is more than 11 times smaller than what is achieved with planar IPD technologies on-glass in Ka-band [3]. For measurement purpose, the circuit has been integrated into the test setup depicted in Fig. 9a. Coupler ports are connected to $50 \Omega \mathrm{CPW}$ access lines and a pair of dual ground-signal-ground (GSGSG) coplanar pads. The measurements have been performed using a Keysight N5247A PNA-X 4-port vector network analyzer (VNA) between $10 \mathrm{GHz}$ to $40 \mathrm{GHz}$ and a pair of $150 \mu \mathrm{m}$ Cascade Infinity GSGSG RF probes.

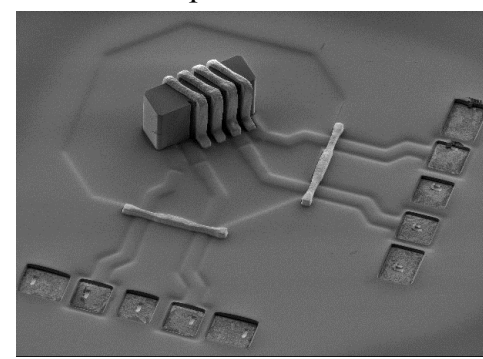

(a)

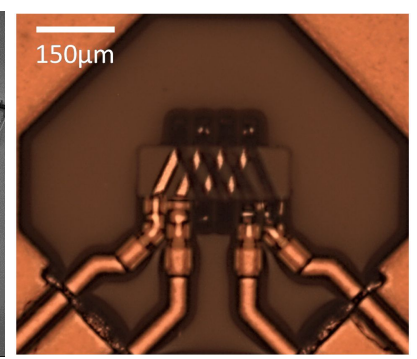

(b)
Fig. 9. Microphotography of the 3-D coupler (a) and top view optical picture (b).

A de-embedding procedure based on [6] and [7] has been developed to shift the reference measurement plane from the probe tips to the end of access lines. For this purpose, two $50 \Omega$ CPW line test patterns of different length have been fabricated. Thanks to these structures, the propagation constant $\gamma$ and the characteristic impedance $Z_{c}$ of the CPW line, as well as pad admittance and serial impedance are extracted and used to remove pad and access contribution from raw measurements.

Simulated, de-embedded measurements, and retro-simulated S-parameters are compared in Fig. 10. First, it can be noticed that measurements agree very well with 
retro-simulated data. The frequency shift observed between initial simulations and measured data is mainly attributed to the contribution of the small wires connecting the coupler ends to the coplanar test fixture. As these four wires are not easy to de-embedded, it has been preferred to show measurements and retro-simulations keeping these small lines. To a lesser extent, the second contribution to this frequency shift is due to technological drifts that occurred during fabrication process (variation of $\mathrm{Si}_{\mathrm{x}} \mathrm{N}_{\mathrm{y}}$ permittivity and transformer dimensions).

A closer analysis of the measured results shows that a $3 \mathrm{~dB} \pm 0.6 \mathrm{~dB}$ coupling efficiency is observed over a wide frequency band, ranging from $19.5 \mathrm{GHz}$ to $26.5 \mathrm{GHz}$. Within this bandwidth, return losses $\left|S_{11}\right|$ and isolation $\left|S_{41}\right|$ range from $-30 \mathrm{~dB}$ to $-14 \mathrm{~dB}$. Considering Fig 11, experimental values of phase shift and amplitude imbalance are reaching $90^{\circ} \pm 3^{\circ}$ and $0.9 \mathrm{~dB}$ respectively, over this whole band. Once technological drifts corrected, this circuit will finally display performances close to simulated results over the $22-30 \mathrm{GHz}$ band. Furthermore, this coupler has been designed to be implemented in a Butler matrix that will addresses beamforming applications in the $5 \mathrm{G}$ frequency bands from $25 \mathrm{GHz}$ to $29 \mathrm{GHZ}$.

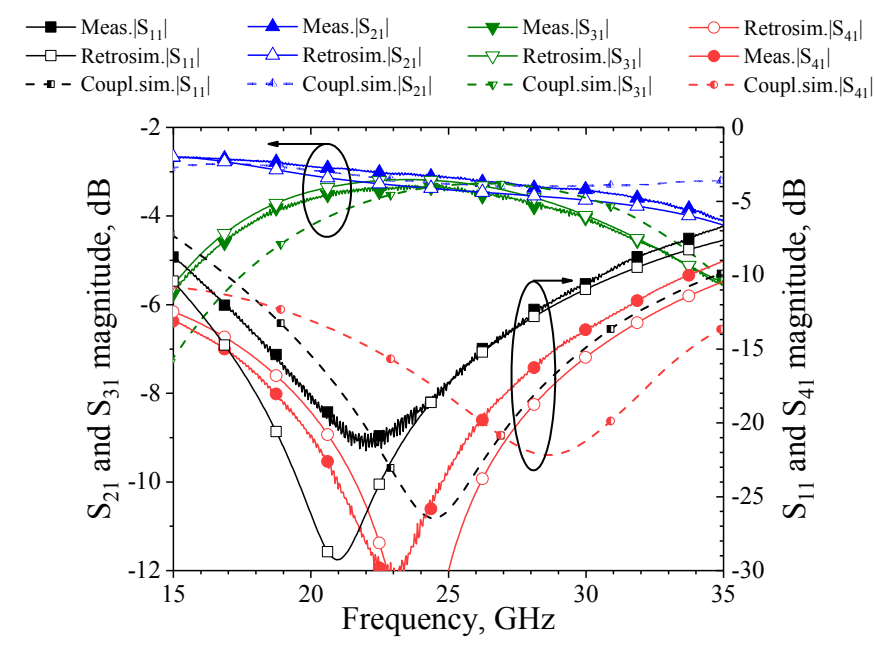

Fig. 10. S-parameter magnitudes for the 3-D coupler.

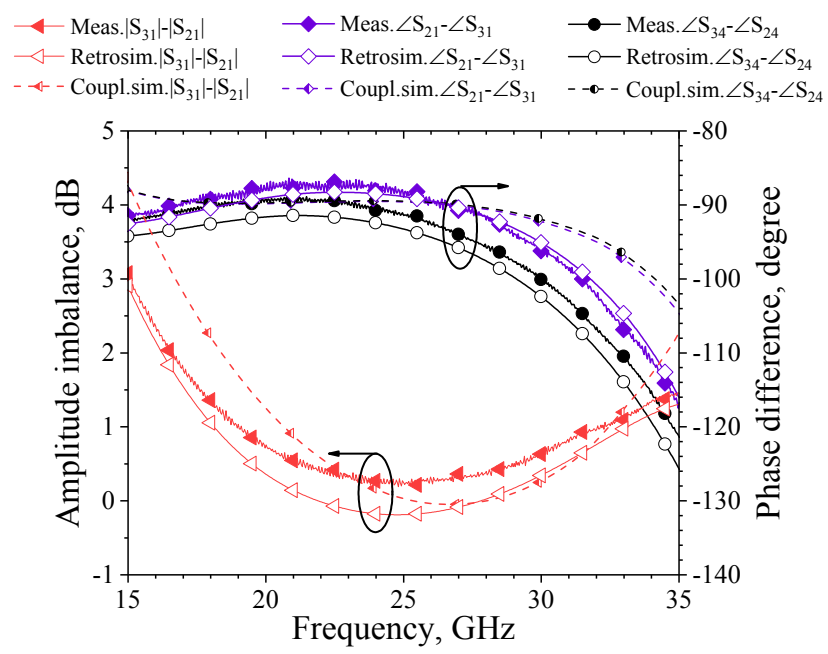

Fig 11. Amplitude imbalance and phase difference for the 3-D coupler.

\section{CONCLUSION}

A compact and wideband $3 \mathrm{~dB}$ quadrature coupler is presented that will address future $5 \mathrm{G}$ applications. The circuit is designed from an optimized 3-D transformer associated with MIM capacitors for an accurate setting of the coupling and matching characteristics. The fabrication is processed by using a dedicated cost-effective low-temperature 3-D IPD technology. Thanks to this process, the total occupied area of the coupler does not exceed $0.11 \mathrm{~mm}^{2}$. The measured performance shows a coupling of $3 \mathrm{~dB}$ with insertion losses better than $0.6 \mathrm{~dB}$, and a phase difference of $90^{\circ} \pm 3^{\circ}$ between outputs over a bandwidth ranging from $19.5 \mathrm{GHz}$ up to 26.5GHz. This coupler with its associated technology offers an unprecedented trade-off between high performances and the overall compactness. It should be particularly interesting for next $5 \mathrm{G}$ applications, as in Butler matrix to address beamforming requirements.

\section{ACKNOWLEDGMENT}

This work is partly supported by LAAS-CNRS micro and nano technologies platform, member of the French RENATECH network. Authors would also like to thank David Bourrier and Alexandre Rumeau for technical supports.

\section{REFERENCES}

[1] S. Wane, L. Leyssenne, O. Tesson, O. Doussin, D. Bajon, D. Lesénéchal, T. V. Dinh, M. P. van Heijden, R. Pijper, P. Magnée, P. Descamps and A. Erdem, "Design of Lange Couplers with local ground references using $\mathrm{SiGe}$ BiCMOS technology for mm-Wave applications," in IEEE Radio Frequency Integrated Circuits Symp. (RFIC), Phoenix, AZ, USA, 2015, pp. 351-354.

[2] C.H. Tseng and Y. T. Chen, "Design and Implementation of New 3-dB Quadrature Couplers Using PCB and Silicon-Based IPD Technologies," IEEE Transactions on Components, Packaging and Manufacturing Technology, vol. 6, no. 5, pp. 675-682, 2016.

[3] C. L. Chang and C. H. Tseng, "Design of 38-GHz branch-line coupler in glass-substrate integrated passive device technology," in IEEE International Symp. on Radio-Frequency Integration Technology (RFIT), Taipei, Taiwan, 2016, pp. 1-3.

[4] F. Tabarani and H. Schumacher, "Compact monolithic spiral quadrature coupler design," in 13th Conference on Ph.D. Research in Microelectronics and Electronics (PRIME), Giardini Naxos - Taormina, Italy, 2017, pp. 181-184.

[5] A. Cayron, C. Viallon, O. Bushueva, A. Ghannam and T. Parra, "High-Performance Compact 3-D Solenoids for RF Applications," IEEE Microwave and Wireless Components Lett., vol. 28, $\mathrm{n}^{\circ}$ 6, pp. 479-481, 2018.

[6] J. E. Zúñiga-Juárez, J. A. Reynoso-Hernández, J. R. Loo-Yau, and M. C. Maya-Sánchez, "An improved two-tier L-L method for characterizing symmetrical microwave test fixtures," Measurement, vol. 44, no. 9, pp. 1491-1498, 2011.

[7] J. A. Reynoso-Hernandez, C. F. Estrada-Maldonado, T. Parra, K. Grenier, and J. Graffeuil "Computation of the Wave Propagation Constant $\gamma$ in Broadband Uniform Millimeter Wave Transmission Line," in Asia Pacific Microwave Conference, Singapore, Singapore, 1999 , pp. 266-269. 